\title{
Modelling chemistry in aircraft plumes 1: comparison with observations and evaluation of a layered approach
}

\author{
Anne Gunn Kraabøla,*, Paul Konopka ${ }^{\mathrm{b}}$, Frode Stordal ${ }^{\mathrm{a}}$, Hans Schlager ${ }^{\mathrm{c}}$

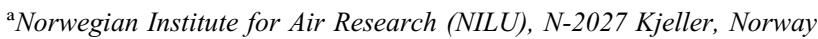 \\ ${ }^{\mathrm{b}}$ Forschungszentrum Jülich GmbH, ICG-1, D-52425 Jülich, Germany \\ 'Institute für Physik der Atmosphäre, Deutsches Zentrum für Luft- und Raumfart (DLR), Oberpfaffenhofen, Germany
}

Received 16 August 1999; received in revised form 6 February 2000; accepted 2 March 2000

\begin{abstract}
An expanding plume model with chemistry has been used to study the chemical conversion of nitrogen oxides to reservoir species in aircraft plumes. The model represents the plume by several circular or cylindrical layers in order to give a more detailed description of the chemical evolution in the plume. Model simulations of plumes from two B747 aircraft monitored during the POLINAT measurement campaigns in winter 1994 and summer 1995 were performed. The $\mathrm{NO}_{x}$ emission indices were 12.5 and $26.1 \mathrm{~g} \mathrm{~kg}^{-1}$, respectively. The chemical evolution was followed during the phase dominated by the aircraft-induced dispersion (vortex regime), and in the atmospheric-induced dispersion regime up to $15 \mathrm{~h}$. The results were compared to observations of $\mathrm{NO}, \mathrm{HNO}_{3}, \mathrm{HNO}_{2}$ and $\mathrm{CO}_{2}$ taken within the trailing vortices. The modelled values were in broad agreement with the observations. With a $\mathrm{NO}_{x}$ emission index of $26.1 \mathrm{~g} \mathrm{~kg}^{-1}, 60 \%$ remained as $\mathrm{NO}_{x}$ after $15 \mathrm{~h}$ at $50^{\circ} \mathrm{N}$ under summer conditions for emissions at $07 \mathrm{UT}$. This amount decreased to $40 \%$ when a one-layered plume was considered, suggesting that the distribution of $\mathrm{NO}_{x}$ leads to different oxidising potentials which again influenced the plume chemistry. (C) 2000 Elsevier Science Ltd. All rights reserved.
\end{abstract}

Keywords: Aircraft emissions; Vortex regime; Dispersion regime; Plume chemistry; Tropospheric chemistry

\section{Introduction}

Over the last couple of years, substantial work has been done in order to understand the chemical and dynamical processes in aircraft plumes (e.g. Danilin et al., 1994; Dürbeck and Gerz, 1995, 1996; Hanisco et al., 1997; Karol and Ozolin, 1994; Karol et al., 1997; Kärcher, 1995; Kärcher et al., 1996; Meijer et al., 1996; Moulik and Milford, 1999; Möllhoff et al., 1996; Petry et al., 1998; Schumann et al., 1995, 1998). The emissions of nitrogen oxides $\left(\mathrm{NO}_{x}=\mathrm{NO}+\mathrm{NO}_{2}\right)$, hydrocarbons $(\mathrm{HC})$ and sulphur dioxide $\left(\mathrm{SO}_{2}\right)$ are gradually converted in the plume, and secondary components, such as e.g. ozone, nitric acid $\left(\mathrm{HNO}_{3}\right)$ and sulphate aerosols, are formed. In order to quantify the chemical and climatic impact of

\footnotetext{
* Corresponding author.

E-mail address: anne.gunn@nilu.no (A.G. Kraabøl).
}

aircraft emissions on a global scale, it is of importance to understand the dispersion and chemical transformations that take place in the aircraft plume before it is homogeneously mixed with the surrounding air.

This article is based on work done within the Pollution from Aircraft Emissions in the North Atlantic Flight Corridor (POLINAT)-projects, and presents findings concerning the chemical conversion of $\mathrm{NO}_{x}$ to reservoir species in aircraft exhaust plumes. Plumes from two different B747s are simulated from a few seconds (s) up to several hours (h) after emission. The model used in our studies describes both the chemical conversions and the dispersion of the exhaust plumes. Similar studies for both subsonic and supersonic aircraft emissions have been performed (Brasseur et al., 1998 and references therein; IPCC, 1999 and references therein). Our approach is to study the chemical evolution in several cylindrical layers, since the plume is not well mixed from 
a cross-sectional point of view. The chemical conversions therefore take place at different rates depending on the distance from the core of the plume.

The aims of the present study were twofold. First, the model results were compared to observations of young plumes of some minutes in order to evaluate the dilution of emitted $\mathrm{NO}_{x}$ and conversion to $\mathrm{HNO}_{3}$ and nitrous acid $\left(\mathrm{HNO}_{2}\right)$. In principle, we are interested in the evolution of the chemistry in plumes of age up to several hours. The chemistry and dispersion in the jet and vortex regimes do, however, govern the concentration and distribution of the emitted species at the start of the dispersion regime. This affects the chemical evolution in the plume on longer time scales. We modelled two cases of emissions from a $\mathrm{B} 747$ with different $\mathrm{NO}_{x}$ and hydroxyl radical $(\mathrm{OH})$ emission indices $(\mathrm{EI})$. In situ measurements of $\mathrm{NO}, \mathrm{HNO}_{3}, \mathrm{HNO}_{2}$ and $\mathrm{CO}_{2}$ mixing ratios in nearfield exhaust plumes were available from the POLINAT measurement campaigns on 13 November 1994 and on 30 June 1995. For the summer case, the modelled $\mathrm{NO}_{x}$ in the plume versus time was also compared to an evolution based on observations suggested by Schumann et al. (1998). The second aim of this study was to investigate the chemical transformation of $\mathrm{NO}_{x}$ in the different layers in the plume and to quantify the effect of representing the plume by several circular or cylindrical layers versus a homogeneous approach. This was also discussed by Petry et al. (1998) and Karol et al. (1997) and their findings will be compared to our results.

In a companion paper, the impact of varying atmospheric conditions on the chemical evolution in aircraft plumes was studied, and suggestions given for how plume-scale processes can be taken into account in mesoscale model studies (Kraabøl and Stordal, 2000).

\section{An expanding plume model with chemistry}

The plume behind an aircraft can be described in three regimes: the jet regime, the vortex regime and the dispersion regime. The present model describes the latter two. Calculations start at the end of the jet regime, i.e. after between 1 and 10s (Hoshizaki et al., 1975). We assume that both at the end of the jet as well as during the vortex regime, the aircraft wakes can be replaced by a single plume with an effective circular cross-section, A. The standard deviation $(\sigma)$ in the concentration of a passive tracer at the start of the vortex regime was chosen to be $6 \mathrm{~m}$. This leads to mixing ratios in accordance with a dilution rate based on observations (Schumann et al., 1998). The breakdown of the vortex structure was set at $124 \mathrm{~s}$ with $\sigma_{\text {vortex }}(t)=20 \mathrm{~m}$ determined from near-field plume measurements (Kraabøl et al., 1999). From the subsequent atmospheric-induced dispersion regime the vertical and horizontal standard deviations are set at 50 and $120 \mathrm{~m}$, respectively (Schumann et al., 1995). Atmos- pheric dispersion is then described using a Gaussian approximation (Konopka, 1995; Schumann et al., 1995):

$$
\begin{aligned}
\sigma_{\mathrm{h}_{\alpha+1}}^{2}= & \frac{2}{3} s_{\alpha}^{2} D_{\mathrm{v}_{\alpha}} \Delta t^{3}+\left(2 s_{\alpha} D_{\mathrm{s}_{\alpha}}+s_{\alpha}^{2} \sigma_{\mathrm{v}_{\alpha}}^{2}\right) \Delta t^{2} \\
& +2\left(s_{\alpha} \hat{\sigma}_{\mathrm{s}_{\alpha}}+D_{\mathrm{h}_{\alpha}}\right) \Delta t+\sigma_{\mathrm{h}_{\alpha}}^{2}, \\
\hat{\sigma}_{\mathrm{s}_{\alpha+1}}= & s_{\alpha} D_{\mathrm{v}_{\alpha}} \Delta t^{2}+\left(s_{\alpha} \sigma_{\mathrm{v}_{\alpha}}^{2}+2 D_{\mathrm{s}_{\alpha}}\right) \Delta t+\hat{\sigma}_{\mathrm{s}_{\alpha}}, \\
\sigma_{\mathrm{v}_{\alpha+1}}^{2}= & 2 D_{\mathrm{v}_{\alpha}} \Delta t+\sigma_{\mathrm{v}_{\alpha}}^{2}, \\
\Delta t:= & t_{\alpha+1}-t_{\alpha}, \quad \alpha=1, \ldots, n-1,
\end{aligned}
$$

where $\sigma_{\mathrm{h}}, \sigma_{\mathrm{v}}$ and $\hat{\sigma}_{\mathrm{s}}$ are the horizontal, vertical and skewed standard deviations, respectively, $t$ is the time and $n$ is a time period where the dispersion parameters are held constant. We assume that $\hat{\sigma}_{\mathrm{s}, 0}=0$ at the start of the dispersion regime. $D_{\mathrm{h}}, D_{\mathrm{v}}$, and $D_{\mathrm{s}}$ are the horizontal, vertical, and skewed diffusion coefficients, respectively, determined according to Dürbeck and Gerz (1996). For the given stratification with a Brunt-Väisällä frequency $N=0.014 \mathrm{~s}^{-1}, \quad D_{\mathrm{h}}=16.7 \mathrm{~m}^{2} \mathrm{~s}^{-1}, \quad D_{\mathrm{v}}=1.1 \mathrm{~m}^{2} \mathrm{~s}^{-1}$ for $3<t<13 \mathrm{~min}$ and $D_{\mathrm{v}}=0.15 \mathrm{~m}^{2} \mathrm{~s}^{-1}$ for $t>13 \mathrm{~min}$. Dürbeck and Gerz (1996) found that $D_{s}$ was rather small compared to a theoretical limit $\left(D_{\mathrm{s}}=\left(D_{\mathrm{v}} D_{\mathrm{h}}\right)^{1 / 2}\right)$. In our work, the relation $D_{\mathrm{s}}=0.5\left(D_{\mathrm{v}} D_{\mathrm{h}}\right)^{1 / 2}$ is assumed. The mean vertical wind shear, $s$, perpendicular to the mean plume is $0.005 \mathrm{~s}^{-1}$.

The Gaussian spreading is, strictly speaking, only valid for a passive tracer. In the model application, the aim is to describe the evolution of chemically active species in the plume. The concentration gradients within the plume can influence this evolution, since the chemistry is nonlinear. The plume is therefore divided into eight circular or elliptical layers parallel to the centreline in order to resolve the cross-sectional concentration distribution (Fig. 1, lower panel, only three layers are shown). The chemical production and loss in each layer is estimated. The chemical module includes 66 compounds and 173 chemical reactions describing the ozone chemistry in the free atmosphere (Kraabøl et al., 1999). This includes $\mathrm{CH}_{4}, \mathrm{CO}, \mathrm{H}_{2} \mathrm{O}, \mathrm{SO}_{2}$ and the following oxygen- $\left(\mathrm{O}\left({ }^{3} \mathrm{P}\right)\right.$, $\left.\mathrm{O}^{1}(\mathrm{D}), \mathrm{O}_{3}\right)$, hydrogen- $\left(\mathrm{H}, \mathrm{H}_{2}, \mathrm{OH}, \mathrm{HO}_{2}, \mathrm{H}_{2} \mathrm{O}_{2}\right)$ and nitrogen compounds $\left(\mathrm{NO}_{y}\right)\left(\mathrm{NO}, \mathrm{NO}_{2}, \mathrm{NO}_{3}, \mathrm{~N}_{2} \mathrm{O}_{5}\right.$, $\mathrm{HNO}_{2}, \mathrm{HNO}_{3}, \mathrm{PAN}\left(\mathrm{CH}_{3} \mathrm{COO}_{2} \mathrm{NO}_{2}\right), \mathrm{HNO}_{4}$, $\mathrm{CH}_{3} \mathrm{O}_{2} \mathrm{NO}_{2}, \mathrm{CH}_{3} \mathrm{ONO}_{2}, \mathrm{C}_{2} \mathrm{H}_{5} \mathrm{ONO}_{2}, \mathrm{C}_{4} \mathrm{H}_{9} \mathrm{ONO}_{2}$ ) as well as the hydrocarbons $\mathrm{C}_{2} \mathrm{H}_{6}, n \mathrm{C}_{4} \mathrm{H}_{10}, \mathrm{C}_{2} \mathrm{H}_{4}$, $\mathrm{C}_{3} \mathrm{H}_{6}, o$-xylene and $\mathrm{C}_{5} \mathrm{H}_{8}$. Several secondary compounds from the oxidation of hydrocarbons are described, which includes the peroxy radicals $\mathrm{CH}_{3} \mathrm{O}_{2}$, $\mathrm{C}_{2} \mathrm{H}_{5} \mathrm{O}_{2}, \mathrm{C}_{4} \mathrm{H}_{9} \mathrm{O}_{2}, \mathrm{CH}_{3} \mathrm{COO}_{2}$. The numerical procedure used is based on the quasi-steady-state approximation (QSSA) (Hesstvedt et al., 1978). Diffusion within the plume is taken into account by estimating the net mass flux of a chemical species through the boundaries of the plume layers. This flux depends on the concentration gradient between the layers, and is further described in Kraabøl et al. (1999). 

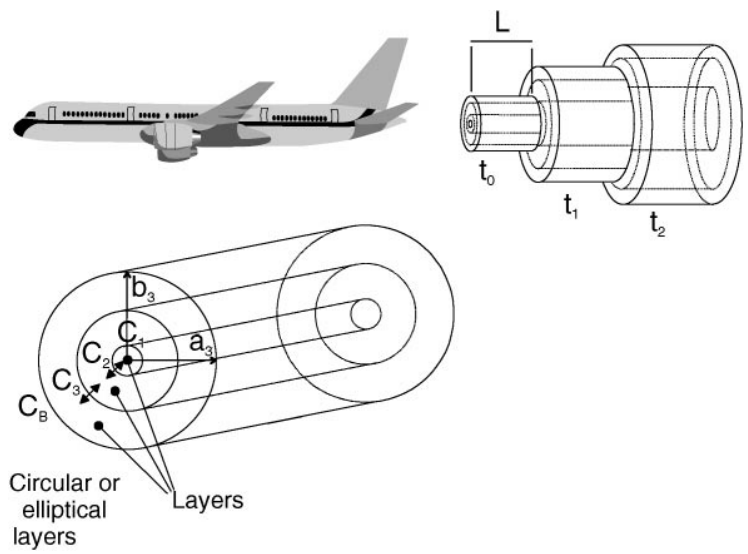

Fig. 1. The upper part shows the plume from a side view at different times $\left(t_{0}, t_{1}, \ldots, t_{n}\right)$. The plume length $L$ was set to $247 \mathrm{~m}$ and is the distance the aircraft travels during $1 \mathrm{~s}$. The lower panel shows a cross-section of the plume. $C_{1}-C_{3}$ indicate the concentration in the plume. (Only three of the eight layers are shown.) The arrows indicate diffusion between the layers in the plume.

The Gaussian approximation is used to describe the horizontal and vertical size of the plume at a given time. The axes from the plume centre to the boundary of the different layers are given as

$a_{i}=r_{i} \sigma_{\mathrm{major}}, \quad b_{i}=r_{i} \sigma_{\mathrm{minor}}$,

where $r_{i}=\frac{3}{8} i, i=1, \ldots, 8$ and $\sigma_{\text {major }}$ and $\sigma_{\text {minor }}$ are the larger and shorter principle axes, respectively (Kraabøl et al., 1999). $L$ is the length of the plume segment, and is set equal to the distance the aircraft travels during $1 \mathrm{~s}$ (Fig. 1, upper panel). The volume of each cylinder, $V$, at time, $t$, with a given length $L$ can be expressed as

$V(t)_{i}=\pi L\left(a_{i} b_{i}-a_{i-1} b_{i-1}\right), \quad a_{0}=b_{0}=0$.

Fig. 2 shows the growth in radius of the various layers versus time with the assumed turbulent conditions. When the plume expands, the boundaries of the layers are redefined and the grid resolution is adjusted, thereby entraining surrounding air and keeping the boundaries in accordance with Eq. (2). The concentrations of the chemical species are redistributed by volume weighting:

$$
\begin{aligned}
& c_{k, i}(t+\mathrm{d} t)= \\
& \frac{c_{k, i}(t)\left(V(t)_{i}-\hat{V}(t+\mathrm{d} t)_{i-1}\right)+c_{k, i+1}(t)\left(\hat{V}(t+\mathrm{d} t)_{i}-V(t)_{i}\right)}{\hat{V}_{i}(t+\mathrm{d} t)-\hat{V}(t+\mathrm{d} t)_{i-1}},
\end{aligned}
$$

where $c_{k, i}$ is the concentration in layer $i$ for species $k$ and $\hat{V}_{i}$ is the volume at $t=t+\mathrm{d} t$ for layer $i$. Note $c_{9}$ is set equal to the background concentration.

\section{Experimental data and initial concentrations}

The model described above is applied to data from two flights of the POLINAT measurement campaigns with the DLR's Falcon research aircraft on 13 November 1994 and 30 June 1995. These two cases will hereafter be referred to as the winter and summer case. The experimental data describing the state of the atmosphere during the chasing of the two B747s, the position of the Falcon, engine type and emission indices are given in Table 1. The emission rate from the $\mathrm{B} 747{\mathrm{in} \mathrm{gs}^{-1}}^{-1}$ calculated based on the fuel consumption per kilometre, the air speed and the EIs for $\mathrm{NO}_{x}, \mathrm{SO}_{2}$, water vapour $\left(\mathrm{H}_{2} \mathrm{O}\right), \mathrm{HC}$ and carbon monoxide $(\mathrm{CO})$ given in Table 1. The distribution of the hydrocarbon emissions is based on suggestions from Pleijel et al. (1993).

The concentrations of oxidants such as $\mathrm{OH}, \mathrm{HO}_{2}$ and $\mathrm{O}$ decrease in the turbine and exhaust nozzle as well as during the jet regime due to chemical processes (e.g. IPCC, 1999; Tremmel et al., 1998; Böckle et al., 1999). Kärcher et al. (1996) have studied the chemical evolution in a B747 exhaust plume during the jet regime. They give a detailed description of the plume chemistry, and sug-
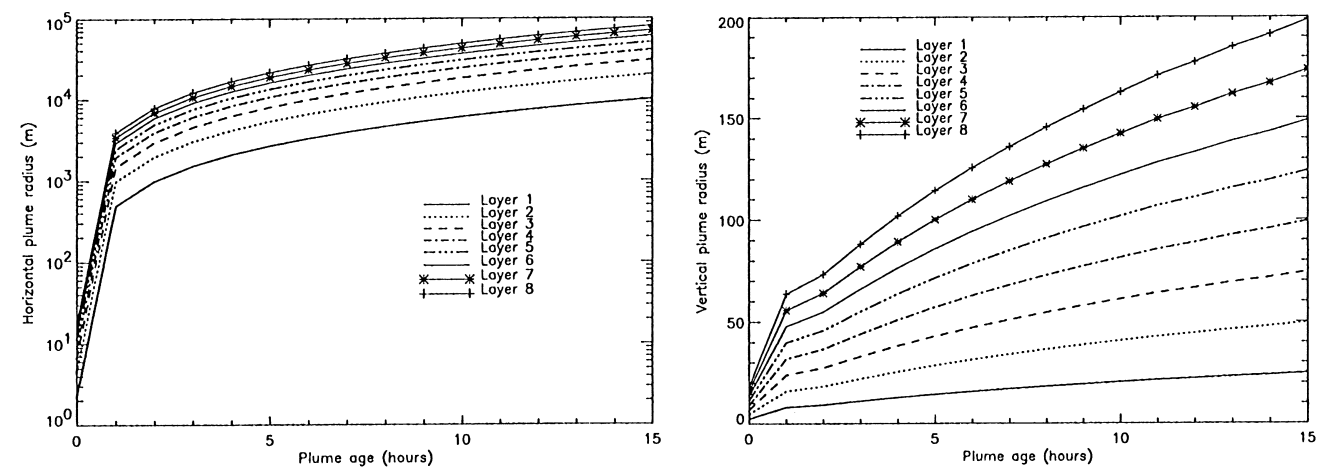

Fig. 2. The growth of the horizontal (left) and vertical (right) plume radius in each layer versus time. 
Table 1

The state of the atmosphere during the chasing of the plumes from the two B747s and the emissions from the considered B747s. Here, $u_{a}$, $v_{a}$ and $s_{u}, s_{v}$ are related to the west-east $(u)$ and south-north $(v)$ directions, respectively. True air speed is the speed relative to the wind speed. The given emission indices are stoichiometric or modelled values. The value of $\mathrm{EI}\left(\mathrm{NO}_{x}\right)=12.5 \mathrm{~g} \mathrm{~kg}^{-1} \mathrm{was}^{\mathrm{based}}$ on near-field plume measurements (Schulte et al., 1997). The data for the chasing on 30 June are taken from Tremmel et al. (1998). (For further information see Tremmel et al. (1998) and references therein)

\begin{tabular}{|c|c|c|c|}
\hline Parameter & Units & 13 November & 30 June \\
\hline Latitude & & $51^{\circ} 20^{\prime} \mathrm{N}$ & $53^{\circ} \mathrm{N}$ \\
\hline Longitude & & $13^{\circ} 1^{\prime} \mathrm{W}$ & $14^{\circ} 30^{\prime} \mathrm{W}$ \\
\hline Assumed emission time & UT & $\approx 14.59$ & $\approx 13.55$ \\
\hline Cruising height $H$ & $\mathrm{~km}$ & 11.25 & 9.2 \\
\hline Temperature $T_{a}$ & $\mathrm{~K}$ & $214 \pm 1$ & 231 \\
\hline NO (observed) & $\mathrm{ppb}$ & 0.130 & 0.0050 \\
\hline $\mathrm{NO}_{2}$ (observed) & ppb & 0.090 & 0.0020 \\
\hline $\mathrm{HNO}_{3}$ (observed) & $\mathrm{ppb}$ & 0.570 & 0.93 \\
\hline $\mathrm{O}_{3}$ (observed) & $\mathrm{ppb}$ & 38 & 118 \\
\hline Engine type & & CF6-80C2B1F & JT9D-7A \\
\hline True air speed $V$ & $\mathrm{~ms}^{-1}, \mathrm{Ma}$ & $247,0.84$ & $247,0.81$ \\
\hline $\mathrm{EI}\left(\mathrm{H}_{2} \mathrm{O}\right)$ & $\mathrm{g} \mathrm{kg}^{-1}$ & 1242.0 & \\
\hline $\mathrm{EI}\left(\mathrm{CO}_{2}\right)$ & $\mathrm{g} \mathrm{kg}^{-1}$ & 3153.0 & \\
\hline $\mathrm{EI}\left(\mathrm{SO}_{2}\right)$ & $\mathrm{g} \mathrm{kg}^{-1}$ & 1.0 & \\
\hline $\mathrm{EI}(\mathrm{CO})$ & $\mathrm{g} \mathrm{kg}^{-1}$ & 1.5 & \\
\hline $\mathrm{EI}\left(\mathrm{NO}_{x}\right)$ & $\mathrm{g} \mathrm{kg}^{-1}$ & 12.5 & 26.1 \\
\hline $\mathrm{EI}(\mathrm{HC})$ & $\mathrm{g} \mathrm{kg}^{-1}$ & 0.2 & \\
\hline Fuel consumption & $\mathrm{kg} \mathrm{km}^{-1}$ & 12.0 & $13.48^{\mathrm{a}}$ \\
\hline
\end{tabular}

${ }^{\mathrm{a}}$ Calculated based on a true air speed of $247 \mathrm{~m} \mathrm{~s}^{-1}$ and fuel flow of $12 \mathrm{th}^{-1}$ taken from Tremmel et al. (1998).

gest the initial conditions at the start of the vortex regime. During the jet regime, $\mathrm{OH}$ and $\mathrm{HO}_{2}$ were removed by reaction with $\mathrm{NO}$ and $\mathrm{NO}_{2}$. $\mathrm{OH}$ was also partly reduced through self-reaction

$\mathrm{OH}+\mathrm{OH}+\mathrm{M} \rightarrow \mathrm{H}_{2} \mathrm{O}_{2}+\mathrm{M}$.

Based on Kärcher et al. (1996) (Figs. 10a, b and 12), we assume that $1.5 \%$ of the emitted NO was converted to $\mathrm{HNO}_{2}, 4 \%$ of the emitted $\mathrm{NO}_{2}$ was converted to $\mathrm{HNO}_{3}$ and that $2.3 \%$ of an $\mathrm{OH}$ value of $6.2 \mathrm{ppmv}$ was converted to $\mathrm{H}_{2} \mathrm{O}_{2}$ in the winter case. In the summer case, $1.5 \%$ of $\mathrm{NO}$ and $3.7 \%$ of $\mathrm{NO}_{2}$ was converted to $\mathrm{HNO}_{2}$ and $\mathrm{HNO}_{3}$, respectively. In this case, $2.3 \%$ of the emitted $\mathrm{OH}$ (9 ppmv) was converted to $\mathrm{H}_{2} \mathrm{O}_{2}$. In our study we interpret these values as the total conversion in both the engine and the jet regime.

Emissions are distributed homogeneously in the volume of the plume at the start of the vortex regime $\left(t=t_{0}\right)$ and added to the concentrations in the background air. The latter were partly initialised by the observed values listed in Table 1 and by diurnal and monthly mean concentrations from a 3-D atmospheric chemistry transport model (Berntsen and Isaksen, 1994). These values were spun up by the plume model for two days in order to get a diurnal variation. Based on previous studies concerning the physics and chemistry in the jet and vortex phase (Louisnard et al., 1995), $t_{0}$ was chosen as $4 \mathrm{~s}$. The initial outer radius of the plume is $18 \mathrm{~m}$ and the plume length is $247 \mathrm{~m}$.

In this study, the formation and evolution of particles is described. Results from a model describing the aerosol nucleation driven by condensation (Ford et al., 1996) are used as input. The time evolution of particles was calculated with a relative humidity of $43 \%$ with respect to liquid water at $214 \mathrm{~K}$. After about $0.1 \mathrm{~s}$ the soot particles in the plume are activated and freeze. The supersaturation in the plume reaches ambient levels after about $20 \mathrm{~s}$. Aerosols melt after about $10 \mathrm{~s}$, and the soot particles emitted stabilise at a radius of $0.09 \mu \mathrm{m}$ with highly acidic compositions. At the start of the calculations, $t=4 \mathrm{~s}$, the total surface area was estimated as $5.54 \times 10^{4} \mu \mathrm{m}^{2} \mathrm{~cm}^{-3}$. After about $1 \mathrm{~h}$ it had decreased to $3.5 \times 10^{-5} \mu \mathrm{m}^{2} \mathrm{~cm}^{-3}$ and reached the ambient level of soot particles, which is assumed to be from $10^{-5}$ to $10^{-2} \mu^{2} \mathrm{~cm}^{-3}$ (IPCC, 1999). Reported surface areas in young contrails of age $0.1-0.5 \mathrm{~s}$ are from $10^{4}$ to $10^{5} \mu \mathrm{m}^{2} \mathrm{~cm}^{-3}$ (IPCC, 1999 and references therein). Kärcher (1997) estimated a total surface area of $6-7 \times 10^{4} \mu \mathrm{m}^{2} \mathrm{~cm}^{-3}$ after $4 \mathrm{~s}$ in the plume. The same evolution of particles is used in all our calculations, although we are aware that other plume mixing rates and meteorological conditions could cause different types of particle evolution in the plume. After the particles melt, we assume that the soot particles are coated 
with sulphuric acid solution $\left(\mathrm{H}_{2} \mathrm{SO}_{4} / \mathrm{H}_{2} \mathrm{O}\right)$ (Kärcher, 1997). The following heterogeneous reaction was assumed to take place on the surface of the ice or coated soot particles:

$\mathrm{N}_{2} \mathrm{O}_{5}+\mathrm{H}_{2} \mathrm{O} \rightarrow 2 \mathrm{HNO}_{3}$.

For coated soot particles the reactive uptake coefficient for sulphate particles was used, and set to 0.1 in accordance with JPL (1997).

\section{Results}

\subsection{Comparison with observations}

The model was applied to the two cases described in Section 3, and compared to near-field measurements. The division of the plume into several layers causes an increasing concentration gradient of the emitted species towards the centre of the plume. As the concentration of the emitted species in the various layers of the plume can differ by an order of magnitude, accurate comparison with observed data is difficult, especially since we do not know exactly where the Falcon penetrated the plumes. Our aim was therefore not to reproduce the near-field observed values, but evaluate the magnitude of difference between the modelled and observed values.

Chemical instrumentation on board the Falcon for the aircraft exhaust plume measurements included a chemiluminescence $(\mathrm{CL})$ detector for $\mathrm{NO}$, a differential nondispersive infrared (NDIR) analyser for $\mathrm{CO}_{2}$, and a chemical ionization mass spectrometer (CIMS) for $\mathrm{HNO}_{2}$ and $\mathrm{HNO}_{3}$. Details on the three instruments and measuring techniques have been described by Schlager et al. (1997), Schulte et al. (1997), and Arnold et al. (1992), respectively. Briefly, the $\mathrm{NO}$ detector uses $\mathrm{NO} / \mathrm{O}_{3}-\mathrm{CL}$ technique including a zero volume upstream of the reaction vessel. Sample air is taken from outside the aircraft via a Teflon inlet line. The pressure in the sampling line is kept constant at $120 \mathrm{hPa}$ by pumping excess air through a pressure-controlled Teflon-valve. The CL reaction chamber is operated at a constant sample gas flow of $31 \mathrm{~min}^{-1}$ (STP) and pressure and $35 \mathrm{hPa}$. For calibration the instrument is supplied with sample air of known NO mixing ratios using $\mathrm{BOC}$ standard $\mathrm{NO} / \mathrm{N}_{2}$ mixtures diluted with zero air. The NDIR instrument includes two absorption cuvettes, an infrared source, and a pneumatic infrared detector. Measuring air is sampled via a Teflon line from outside the aircraft and compressed to $1.1 \mathrm{~atm}$ by a diaphragm pump before being passed through one of the cuvettes. The second cuvette is flushed with a reference mixture of $380 \mathrm{ppmv} \mathrm{CO}_{2}$ in dry air. For calibration the instrument is supplied with pre-prepared $\mathrm{CO}_{2} /$ air standards. In the CIMS instrument, $\mathrm{HNO}_{2}$ and $\mathrm{HNO}_{3}$ are ionised by specific ion-molecule reactions in a flow tube attached to a quadrupole mass spectrometer. The mass spectrometer is pumped by a liquid-neon-cooled cryopump. The reactant ions are produced by a highfrequency glow discharge and injected into the flow tube. The $\mathrm{HNO}_{2}$ and $\mathrm{HNO}_{3}$ abundances are calculated from the measured ratios of product and reactant ions, the reaction rate coefficient, and the ion residence time in the flow tube. The estimated accuracies for the measurements of $\mathrm{CO}_{2}, \mathrm{NO}, \mathrm{HNO}_{2}$, and $\mathrm{HNO}_{3}$ enhancements in the aircraft exhaust plumes are $8,6,50$, and $50 \%$, respectively.

The aircraft plume measurements were performed off the west coast of Ireland in the Shannon Radar Control Zone for the transatlantic air traffic. The chasing procedures of specific source aircraft are described by Schulte et al. (1997). During the chasing of a B747 on 13 November 1994, maximum NO concentrations were measured in the two vortices, which descended about $150 \mathrm{~m}$ from the cruising altitude of the source aircraft due to wake dynamics. The remaining NO data were mostly obtained from the so-called secondary plume, a diffuse curtain of emissions which were detrained or originally not trapped by the vortices. For comparison with the plume model simulations, only the observations in the vortices are used.

Fig. 3 shows the modelled evolution of $\mathrm{NO}$ in the plume of the B747 during the first 4 min for the winter case. When the vortex structure breaks down, the mixing ratio dropped in all the layers of the plume due to a rapid plume expansion causing a high entrainment of surrounding air. During the first $3 \mathrm{~min}, \mathrm{NO}$ in the innermost layer decreased from 427 to $\sim 4$ ppbv. The Falcon only penetrated the trailing vortices once, when the plume was $83 \mathrm{~s}$ old. The measured NO was $59 \pm 5 \mathrm{ppb}$ and the modelled values in the five inner layers of the plume ranged from 112 to $42 \mathrm{ppb}$. The modelled values in

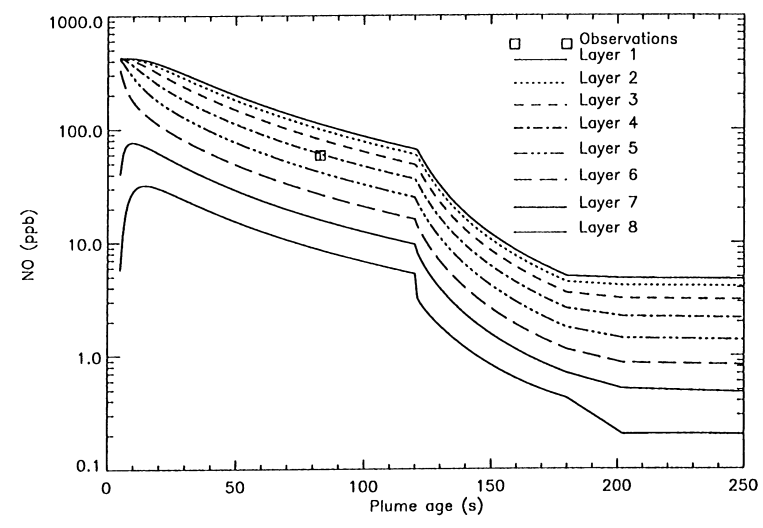

Fig. 3. The measured NO concentrations (squares) in the plume from a B747 on 13 November 1994 compared with the concentrations calculated with the plume model in the different layers. 

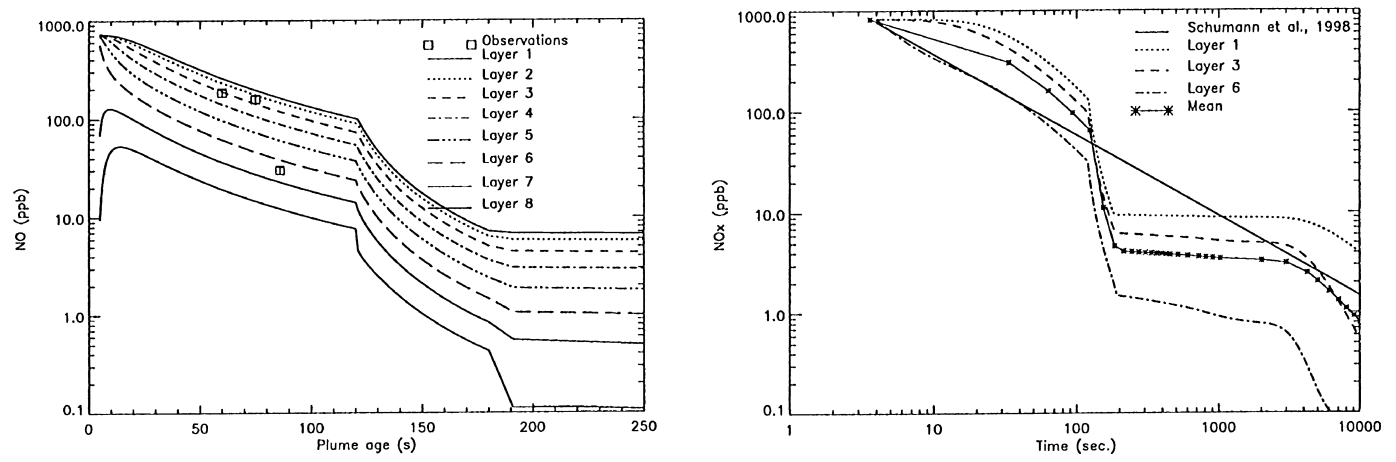

Fig. 4. Left panel: The same as Fig. 3, but for the plume chasing on 30 June 1995. Right panel: The mixing ratio of $\mathrm{NO}_{x}$ versus time after emission in the different layers. The solid line represents the values calculated with Eq. (7). The diamonds correspond to the mean value of $\mathrm{NO}_{x}$ in the plume.

the middle part of the plume were in agreement with the observed NO.

For the summer case, the vortices were penetrated three times. Fig. 4, left panel, shows the NO value in the various layers of the plume together with observations during the first $4 \mathrm{~min}$. The modelled values in the four inner layers ranged from 264 to 143 and 203 to $110 \mathrm{ppb}$ after 59 and $75 \mathrm{~s}$ of calculations, respectively. This was in reasonable agreement with the observed maximum of $184 \pm 15$ and $158 \pm 12 \mathrm{ppb}$ at the same times.

For both comparisons, the modelled values in the innermost part of the plumes are high compared to the observations. These observations are taken within the trailing vortices, but normally such observations were avoided due to high turbulence (Schulte et al., 1997). Since we do not know if the penetrations reached the core of the plume, we allow a somewhat higher concentration in the inner layers. Schulte et al. (1997) report nighttime measurements of NO concentration up to $318 \mathrm{ppb}$, between 61 and $104 \mathrm{~s}$ after emissions associated with an EI $\left(\mathrm{NO}_{x}\right)$ of $17 \mathrm{~g} \mathrm{~kg}^{-1}$ and a fuel flow ratio of $10.4 \mathrm{th}^{-1}$. This might indicate that higher plume values than $184 \mathrm{ppb}$, which were measured, could have occurred given the aircraft $\mathrm{EI}\left(\mathrm{NO}_{x}\right)$ of $26.1 \mathrm{~g} \mathrm{~kg}^{-1}$ and flow fuel ratio of $13.6 \mathrm{th}^{-1}$.

For the summer case, we have compared the modelled $\mathrm{NO}_{x}$ mixing ratio versus time with a time evolution suggested by Schumann et al. (1998),

$\delta r_{\mathrm{NO}_{x}}=\frac{\mathrm{EI}\left(\mathrm{NO}_{x}\right) M_{\mathrm{air}}}{M_{\mathrm{NO}_{x}} N}, \quad N=7000\left(\frac{t}{t_{0}}\right)^{0.8}$,

where $\delta r_{\mathrm{NO}_{x}}$ is the mixing ratio of $\mathrm{NO}_{x}, M_{\text {air }}$ and $M_{\mathrm{NO}_{x}}$ the molecular weight of air and $\mathrm{NO}_{2}$, respectively. $N$ is the bulk dilution rate. Fig. 4, right panel, shows the change in volume mixing ratio of $\mathrm{NO}_{x}$ in the inner and outer parts of the plume at approximately $3 \mathrm{~h}$ after emission. In the vortex regime, the modelled concentration in the inner part of the plume was about five times higher than the concentration calculated by Eq. (7) (solid line). As pointed out by Schumann et al. (1998), $N$ is the bulk dilution ratio based on measurements in more than 70 plumes. The fit is best for young plumes of age from 1 to $50 \mathrm{~s}$, and may deviate by a factor of 3-5 from Eq. (7). The evolution suggested by Schumann et al. (1998) was, however, in fair agreement with the time evolution of the modelled mean $\mathrm{NO}_{x}$ in the plume (diamonds). The highest deviation was found after the breakdown regime ( 3 min after emission). As discussed in Schumann et al. (1995), the vortex regime can last from 3 to $5 \mathrm{~min}$. If we delay the modelled breakdown by 2 min, the mean $\mathrm{NO}_{x}$ value in the plume was $16 \mathrm{ppb}$ after $3 \mathrm{~min}$. This is within the uncertainty limit given for Eq. (7). We found, however, that allowing a longer vortex period did not have any significant impact on the amount of $\mathrm{NO}_{x}$ converted to reservoir species on longer time scales.

Fig. 5 shows the observed values of $\mathrm{HNO}_{3}$ and $\mathrm{HNO}_{2}$ together with modelled data for the summer case. As seen for $\mathrm{NO}$, the modelled $\mathrm{HNO}_{2}$ in the middle part of the plume was in agreement with the observed value of $2.6 \pm 1.6$ and $2.3 \pm 1.1 \mathrm{ppb}$ after 59 and $75 \mathrm{~s}$, respectively. $\mathrm{HNO}_{3}$ observations were only available after $59 \mathrm{~s}$. The observed $\mathrm{HNO}_{3}$ concentration was $1.3 \pm 0.6 \mathrm{ppb}$, while the model results ranged from $2.1 \mathrm{ppb}$ (innermost layer) to $1.3 \mathrm{ppb}$ (layer 5) at the same time.

The measured $\mathrm{CO}_{2}$ concentrations above the background in the vortices were $25.4 \pm 1.5,21 \pm 1.3$ and $4.8 \pm 0.3 \mathrm{ppm}$ at 59,75 and $86 \mathrm{~s}$, respectively (not shown). The background concentration was $362 \mathrm{ppm}$ (Tremmel et al., 1998). The modelled values above the background in the four inner layers of the plume at the same times ranged from 40.4 to $22.2,30.5$ to 16.7 and 25 to $16.7 \mathrm{ppm}$.

These comparisons indicate that the model is able to estimate reasonable values of $\mathrm{NO}, \mathrm{HNO}_{2}, \mathrm{HNO}_{3}$ and 

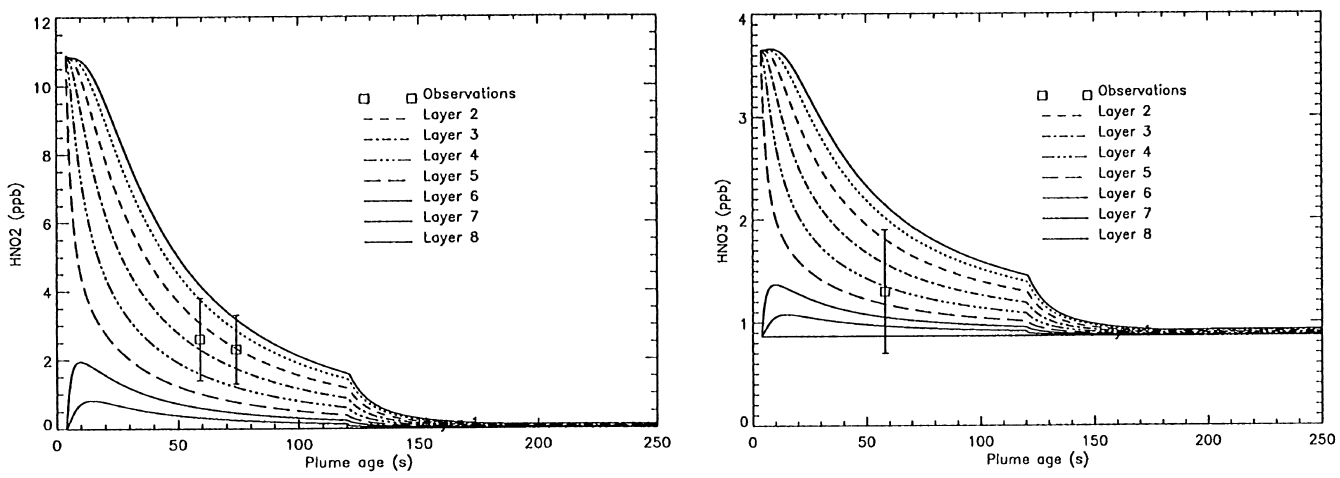

Fig. 5. The same as Fig. 4 left panel, but for $\mathrm{HNO}_{2}$ (left panel) and $\mathrm{HNO}_{3}$ (right panel).

$\mathrm{CO}_{2}$ with respect to the concentrations measured in the vortices of young aircraft plumes.

\subsection{Chemical conversion to reservoir species in the different layers of the plume}

The aircraft plume in the summer case, was followed for $15 \mathrm{~h}$. We assume that the plume was emitted at $07 \mathrm{UT}$ at $50^{\circ} \mathrm{N}$ and $0^{\circ} \mathrm{W}$ in July. The temperature was set to $230 \mathrm{~K}$. The $\mathrm{NO}_{x}$ conversion to reservoir species like $\mathrm{HNO}_{3}$, methyl-peroxynitrate $\left(\mathrm{CH}_{3} \mathrm{NO}_{4}\right), \mathrm{PAN}$ and peroxynitric acid $\left(\mathrm{HNO}_{4}\right)$ in the different layers of the plume was investigated for the $15 \mathrm{~h}$ period. Table 2 lists concentrations of some key species in the plume and in the background air at noon and midnight. Diurnal variations of the concentrations in the background air are taken into account in the model calculations.

To study the role of the chemistry, two model runs were compared: a run with emissions (A) and a run without emissions (B). In run B, we follow an imaginary plume with the same dispersion and mixing with ambient air as in run A. The purpose was to simulate the natural chemical diurnal variations along the plume trajectory. In this case, the concentration in the 'plume' is very similar to the concentration in the ambient air, but can differ if the plume is advected over large distances. The emission rate of $\mathrm{NO}_{x}$ was $81.6 \mathrm{~g} \mathrm{~s}^{-1}$ and this gives $1.05 \times 10^{24} \mathrm{NO}_{x}$ molecules emitted at the engine exit. By studying the decrease in the emitted $\mathrm{NO}_{x}$ and the corresponding increase in reservoir species, it is possible to quantify the amount of the emitted $\mathrm{NO}_{x}$, which is converted to reservoir species versus time. For this purpose, the following equation was used:

$f(t)_{k, i}=V(t)_{i}\left[c(t)_{k, i(\mathrm{~A})}-c(t)_{k, i(\mathrm{~B})}\right]$,

where $f(t)_{k, i}$ gives the difference in numbers of molecules between the runs for a species $k$ in a layer $i$ versus time $(t)$. Suffixes A and B refer to runs with and without emis-
Table 2

Initial concentrations in the plume and concentrations in the ambient air at noon and midnight. Numbers not reported are below 1 ppt

\begin{tabular}{lcl}
\hline $\begin{array}{l}\text { Initial } \\
\text { concentration }\end{array}$ & Plume & $\begin{array}{l}\text { Background } \\
\text { Noon/midnight }\end{array}$ \\
\hline $\mathrm{NO}(\mathrm{ppb})$ & 730 & 0.034 \\
$\mathrm{NO}_{2}(\mathrm{ppb})$ & 98 & $0.012 / 0.046$ \\
$\mathrm{HNO}_{3}(\mathrm{ppb})$ & 3.1 & $0.32 / 0.33$ \\
$\mathrm{OH}(\mathrm{ppt})$ & & 0.40 \\
$\mathrm{HO}_{2}(\mathrm{ppt})$ & & 3.60 \\
$\mathrm{O}_{3}(\mathrm{ppb})$ & 85.2 & $85.4 / 85.6$ \\
$\mathrm{PAN}(\mathrm{ppb})$ & 0.25 & $0.25 / 0.26$ \\
$\mathrm{HCHO}(\mathrm{ppb})$ & 1.18 & $0.056 / 0.060$ \\
$\mathrm{CO}^{(p p b m)}$ & 2.56 & $113 / 113$ \\
$\mathrm{C}_{2} \mathrm{H}_{4}(\mathrm{ppt})$ & 2.37 & $1.43 / 0.82,19^{\mathrm{a}}$ \\
$\mathrm{C}_{2} \mathrm{H}_{6}(\mathrm{ppb})$ & 2.10 & $2.04 / 2.03$ \\
$\mathrm{C}_{3} \mathrm{H}_{6}(\mathrm{ppb})$ & 0.48 & $0.002^{\mathrm{a}}$ \\
$\mathrm{NC}_{4} \mathrm{H}_{10}(\mathrm{ppb})$ & 0.8 & $0.028^{\mathrm{a}}$ \\
$o-\mathrm{xylene}(\mathrm{ppb})$ & 0.12 & $0.002^{\mathrm{a}}$ \\
$\mathrm{C}_{3} \mathrm{H}_{8}(\mathrm{ppt})$ & & $6.3^{\mathrm{a}}$ \\
\hline
\end{tabular}

${ }^{a}$ The diurnal monthly mean concentrations of short-lived hydrocarbons are given, since the concentrations were reduced during the modelled spin-up time.

sions, respectively. Mixing with ambient air is the same for both runs, so that $f(t)_{\mathrm{NO}_{y}}$ for the whole plume is the sum of emitted $\mathrm{NO}_{x}$, and is constant in time. By studying e.g. the fraction $\sum_{i=1}^{8} f(t)_{\mathrm{HNO}_{3}, i} / f(t)_{\mathrm{NO}_{y}}$ or $f(t)_{\mathrm{HNO}_{3}, i}$ $f(t)_{\mathrm{NO}_{y}}$ it is possible to quantify the fraction of the emitted $\mathrm{NO}_{x}$ which is chemically converted to $\mathrm{HNO}_{3}$ versus time in the whole plume or in a layer. This approach was used in the results shown in Fig. 6, Tables 3 and 4.

It is important to stress that the results shown are not sensitive to the chosen length $(L)$ of the plume segment (Fig. 1). For a given emission index, fuel consumption and aircraft speed, a shorter length gives a lower emission rate, but the initial volume of the plume will also decrease 

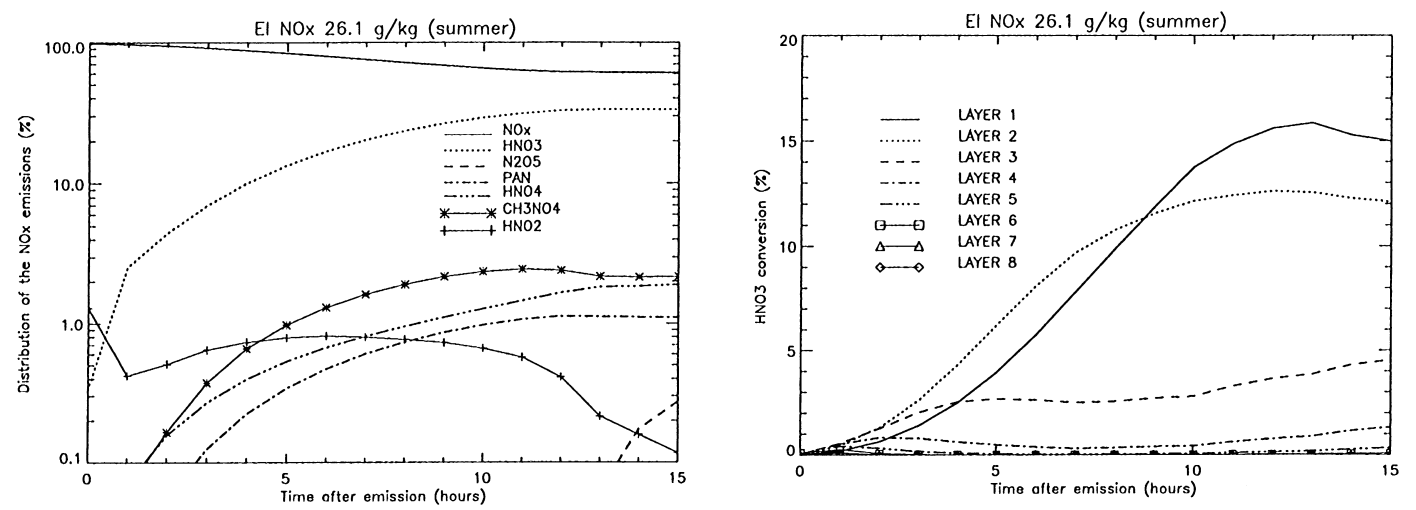

Fig. 6. Left panel: The estimated chemical conversion of the emitted $\mathrm{NO}_{x}\left(26.1 \mathrm{~g} \mathrm{~kg}^{-1}\right)$ to the different species in the odd nitrogen family versus time. Right panel: The percentage conversion to $\mathrm{HNO}_{3}$ in the different layers of the plume versus time.

Table 3

The amount of the emitted $\mathrm{NO}_{x}$ remaining as $\mathrm{NO}_{x}$ after $15 \mathrm{~h}$ in a layered and a homogeneous plume for different background concentrations of $\mathrm{NO}_{x}$ and ozone

\begin{tabular}{|c|c|c|c|c|}
\hline \multirow[t]{3}{*}{$\mathrm{NO}_{x}(\mathrm{ppt})$} & \multicolumn{4}{|l|}{ Ozone (ppb) } \\
\hline & \multicolumn{2}{|l|}{50} & \multicolumn{2}{|l|}{150} \\
\hline & Layered (\%) & Homogeneous $(\%)$ & Layered (\%) & Homogeneous $(\%)$ \\
\hline 50 & 65 & 51 & 60 & 33 \\
\hline 150 & 67 & 51 & 66 & 42 \\
\hline
\end{tabular}

Table 4

The same as Table 3, but for different times of emissions. The $\mathrm{NO}_{x}$ and ozone background concentrations were $150 \mathrm{ppt}$ and $150 \mathrm{ppb}$, respectively

\begin{tabular}{lll}
\hline Time (UT) & Layered $(\%)$ & Homogeneous $(\%)$ \\
\hline 1 & 57 & 41 \\
5 & 60 & 39 \\
9 & 72 & 50 \\
13 & 84 & 72 \\
17 & 80 & 79 \\
21 & 57 & 56 \\
\hline
\end{tabular}

since the aircraft covers a shorter distance. The concentration at the start of the calculations is therefore not influenced by the length of the plume.

Fig. 6, left panel, shows the distribution of the $\mathrm{NO}_{x}$ emissions with time for the plume seen as a whole. After $15 \mathrm{~h}, 40 \%$ of the emitted $\mathrm{NO}_{x}$ was converted to reservoir species, mainly $\mathrm{HNO}_{3}$. The highest conversion was calculated in the two inner layers of the plume during most of the $15 \mathrm{~h}$ period (Fig. 6, right panel).

The second most important reservoir was $\mathrm{CH}_{3} \mathrm{NO}_{4}$. This compound is formed by reaction between $\mathrm{CH}_{3} \mathrm{O}_{2}$ and $\mathrm{NO}_{2}$, and is thermally unstable. The temperature used in this case was $231 \mathrm{~K}$, and the lifetime of $\mathrm{CH}_{3} \mathrm{NO}_{4}$ was about $6 \mathrm{~h}$. Reaction- and photolyis rates are adapted from Atkinson et al. (1997) and JPL (1997), respectively. After $15 \mathrm{~h}, 2 \%$ of the $\mathrm{NO}_{x}$ was converted to this compound. The conversion to $\mathrm{HNO}_{4}$ by the reaction between $\mathrm{NO}_{2}$ and $\mathrm{HO}_{2}$, also amounted to about $2 \%$. This conversion was faster in the outer parts of the plumes. The reaction

$\mathrm{NO}+\mathrm{HO}_{2} \rightarrow \mathrm{NO}_{2}+\mathrm{OH}$

caused a stronger decrease in $\mathrm{HO}_{2}$ in the inner layers due to higher NO. The conversion to PAN was small in all layers due to a limited availability of the $\mathrm{CH}_{3} \mathrm{COO}_{2}$ needed for PAN conversion. Furthermore, the build up of dinitrogenpentoxide $\left(\mathrm{N}_{2} \mathrm{O}_{5}\right)$ was low in all the layers after $15 \mathrm{~h} . \mathrm{N}_{2} \mathrm{O}_{5}$ is easily dissociated by UV-radiation and is not a reservoir for $\mathrm{NO}_{x}$ during daytime. The conversion of $\mathrm{NO}$ to $\mathrm{HNO}_{2}$ in the jet regime was set to $1.3 \%$. After $15 \mathrm{~h}$, the fraction had decreased and the loss of $\mathrm{HNO}_{2}$ was higher than the production.

Möllhoff et al. (1996) used a plume model to study emissions at $50^{\circ} \mathrm{N}$ under June conditions. The $\mathrm{NO}_{x}$ emission index was $21.2 \mathrm{~g} \mathrm{~kg}^{-1}$. For emissions at 08 local time they 
calculated the following distribution after $15 \mathrm{~h}, 70 \%$ as $\mathrm{NO}_{x}, 23 \%$ as $\mathrm{HNO}_{3}, 5 \%$ as $\mathrm{HNO}_{4}$ and $2 \%$ as $\mathrm{N}_{2} \mathrm{O}_{5}$ (based on Fig. 3, right panel in Möllhoff et al., 1996). We used the same emission time, temperature $(214 \mathrm{~K})$ and a background concentration of $\mathrm{NO}_{x}$ of $150 \mathrm{ppt}$, and estimated $75 \%$ as $\mathrm{NO}_{x}$ and $24 \%$ as $\mathrm{HNO}_{3}$ after $15 \mathrm{~h}$. The total conversion to reservoir species is comparable, but in this work the build-up of $\mathrm{HNO}_{4}$ was lower. This might be due to different values of $\mathrm{HO}_{2}$ in the ambient air. As explained above, the conversion to this compound was faster in the outer layers of the plume, and is therefore strongly influenced by the concentrations in the surrounding air.

Meijer et al. (1996) used a layered plume model and estimated the following distribution after $15 \mathrm{~h}$ for emissions at noon at $50^{\circ} \mathrm{N}$ under July conditions; $75 \%$ as $\mathrm{NO}_{x}, 15 \%$ as $\mathrm{HNO}_{3}$ and $10 \%$ as $\mathrm{N}_{2} \mathrm{O}_{5}$. The $\mathrm{NO}_{x}$ background was $50 \mathrm{ppt}$ and the $\mathrm{NO}_{x}$ emission index was $16 \mathrm{~g} \mathrm{~kg}^{-1}$. For the same conditions, but with $\mathrm{EI}\left(\mathrm{NO}_{x}\right)=12.5 \mathrm{~g} \mathrm{~kg}^{-1}$, our modelled distribution was $77 \%$ as $\mathrm{NO}_{x}, 20 \%$ as $\mathrm{HNO}_{3}, 0.5 \%$ as $\mathrm{N}_{2} \mathrm{O}_{5}$ and $3.5 \%$ as $\mathrm{HNO}_{4}$. As in the first comparison, the modelled conversion of $\mathrm{NO}_{x}$ was in good agreement, but with less build-up of $\mathrm{N}_{2} \mathrm{O}_{5}$. The reason for the discrepancy could be the different turbulent conditions used in the two studies. Meijer et al. (1996) calculated the dispersion of the plume using a Gaussian approximation, but did not include vertical shear. In our studies, vertical shear implies a higher plume dispersion rate and, hence, a faster dilution of the emitted $\mathrm{NO}_{x}$. For emissions at noon, the $\mathrm{NO}_{2}$ concentration will be lower in the plume during night in our study and this might explain the reduced conversion to $\mathrm{N}_{2} \mathrm{O}_{5}$.

The chemical conversion to $\mathrm{HNO}_{3}$ in the different layers is dependent on the concentrations of $\mathrm{OH}$ and $\mathrm{NO}_{x}$. Fig. 7, left panel, shows the evolution of $\mathrm{OH}$ in the five innermost layers of the plume and in the background during the $15 \mathrm{~h}$ calculation. $\mathrm{OH}$ at the engine exit was assumed to be converted to $\mathrm{HNO}_{2}, \mathrm{HNO}_{3}$ and $\mathrm{H}_{2} \mathrm{O}_{2}$ during the jet regime. Although a homogeneous distribution of the emissions was assumed at the start of the vortex regime, the evolution of $\mathrm{OH}$ was different in the various layers. The maximum rise in $\mathrm{OH}$ above the background occurred in layer 2 about $6 \mathrm{~h}$ after emissions. $\mathrm{OH}$ was $60 \%$ higher than the value in the background air. In layer 1, the $\mathrm{OH}$ value was below background for the whole period. The concentration started to increase about $1 \mathrm{~h}$ after emissions due to both photochemical production and mixing with ambient air. After $12 \mathrm{~h}$ the sun set, and this caused a strong decline in $\mathrm{OH}$ concentration in both the plume and the background air.

The evolution of $\mathrm{OH}$ in the plume was closely linked to the evolution of ozone in the different layers (Fig. 7, right panel). At the start of the calculations, the ozone level dropped in all the layers due to reaction with NO. Fig. 8 shows that the highest $\mathrm{NO}_{x}$ concentration was estimated in the innermost layer of the plume, and this caused the most pronounced ozone drop. Due to both mixing with ambient air and chemical production, the levels thereafter increased differentially in the layers. In the innermost layer, ozone reached a maximum about $12 \mathrm{~h}$ after emissions. There was probably a potential for higher ozone, but with sun set, ozone concentrations approached background. The most efficient ozone production was calculated in layer 2, where the highest $\mathrm{OH}$ increase also was calculated (Fig. 7).

The heterogeneous reaction (6) had little influence on the conversion of $\mathrm{NO}_{x}$ to reservoir species, and thereby the ozone chemistry in the plume as reported elsewhere (e.g. Moulik and Milford, 1999; Danilin et al., 1994; Karol and Ozolin, 1994).

Petry et al. (1998) calculated effective emission indices of reservoir species in aircraft plumes using a Gaussian approach. In contrast to our findings, they found that dividing the plume into different layers did not have a significant effect on the conversion of the emitted $\mathrm{NO}_{x}$
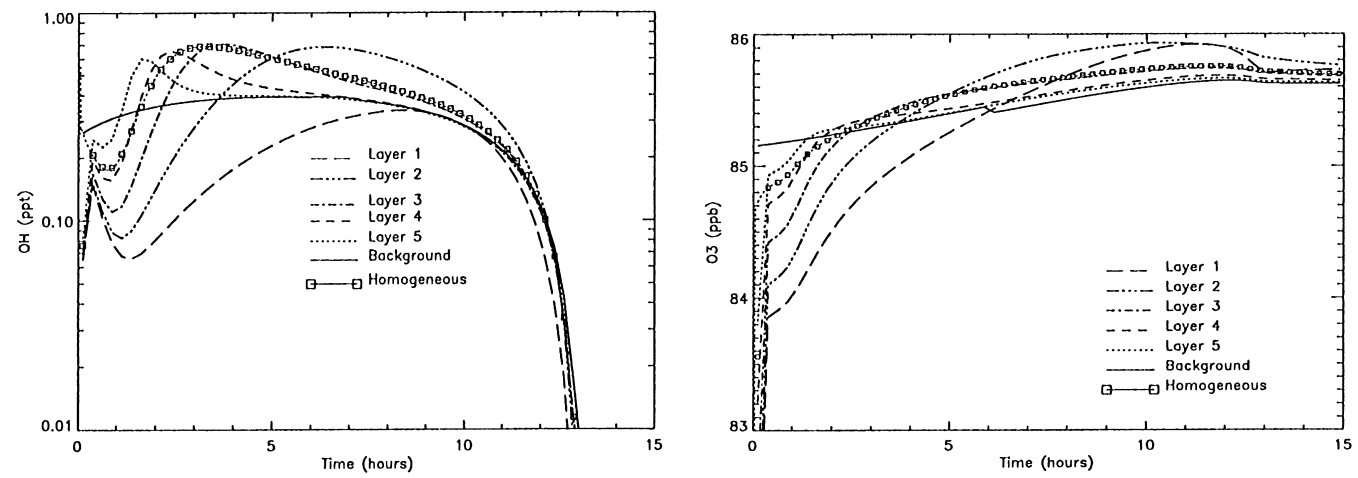

Fig. 7. The evolution of $\mathrm{OH}$ and ozone in the five innermost layers of the plume and the background air from $4 \mathrm{~s}$ and up to $15 \mathrm{~h}$. (The squares show the evolution in a homogeneous plume.) 


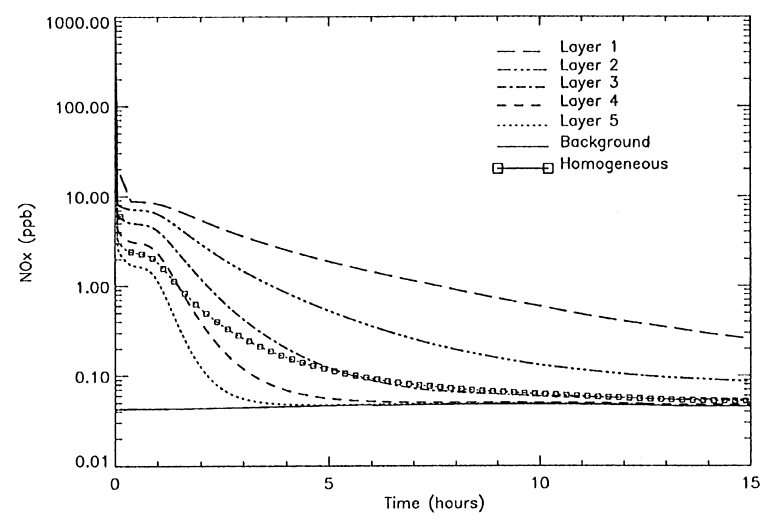

Fig. 8. The same as Fig. 7, but for $\mathrm{NO}_{x}$.

or on the ozone concentration in the plume. Karol et al. (1997) used both a box model and a Gaussian plume model to study the chemistry in exhaust plumes and their findings support Petry et al. (1998). In both works the emissions are assumed to take place at $50^{\circ} \mathrm{N}$ at summer conditions as in the work reported here. When using a homogeneous approach, we find that $42 \%$ of the $\mathrm{NO}_{x}$ emissions remained as $\mathrm{NO}_{x}$ after $15 \mathrm{~h}$, while this amount increased to $60 \%$ in the layered plume. Fig. 8 shows the evolution of $\mathrm{NO}_{x}$ in the homogeneous plume (solid lines with squares). The mixing ratio of NO was lower compared to the inner part of the layered plume, causing a slower ozone titration with NO compared to these layers. The ozone production was more efficient in the homogeneous plume, and the maximum ozone increase above background was estimated about $2 \mathrm{~h}$ after emissions (Fig. 7, right panel, solid lines with squares). This again favoured $\mathrm{OH}$ production in the plume. Fig. 7 shows that the $\mathrm{OH}$ level in the homogeneous plume was higher than the background for a longer time period than what was the case in the layered plume. This caused a higher conversion to $\mathrm{HNO}_{3}$ compared to the layered plume. In addition, the conversion to $\mathrm{HNO}_{4}$ was also higher in the former case. A smaller amount of $\mathrm{HO}_{2}$ was lost in reaction with NO compared to the layered plume.

We have also compared a layered versus a homogeneous approach for different background concentrations of $\mathrm{NO}_{x}$ and ozone (Table 3). In both approaches, the chemical conversion of $\mathrm{NO}_{x}$ to reservoir species increased with a higher ozone concentration in the ambient air. In addition, the difference in the chemical conversion of $\mathrm{NO}_{x}$ between the two approaches was enhanced. With a high ozone concentration, the conversion of $\mathrm{NO}_{x}$ to $\mathrm{HNO}_{4}, \mathrm{PAN}$ and $\mathrm{CH}_{3} \mathrm{NO}_{4}$ increased in the plume. At the start of the calculations, NO reacts with ozone and converts more of the emitted $\mathrm{NO}$ to $\mathrm{NO}_{2}$, when background ozone is higher. Since $\mathrm{HO}_{2}, \mathrm{CH}_{3} \mathrm{COO}_{2}$ and $\mathrm{CH}_{3} \mathrm{O}_{2}$ can all react with $\mathrm{NO}$, this conversion will re- duce the decrease in these compounds which are needed for $\mathrm{HNO}_{4}, \mathrm{PAN}$ and $\mathrm{CH}_{3} \mathrm{NO}_{4}$ production, respectively. This effect was more distinct when a homogeneous plume approach was used.

Table 4 lists the results from homogeneous and layered plume calculations for different times of emissions. The difference in the chemical conversion of $\mathrm{NO}_{x}$ after $15 \mathrm{~h}$ showed a strong diurnal variation. The greatest difference was found for emissions in the morning, and the least for emissions in the afternoon.

It should be noted that the time the plume is followed strongly affects the difference between a layered and a homogeneous approach. Like Karol et al. (1997), we find little difference between the two approaches after $1 \mathrm{~h}$ of calculations. In our case, the conditions for ozone production in the plume govern the magnitude of difference between the approaches. The potential for ozone production during daylight is dependent on the ratio between $\mathrm{NO}_{x}$ and non-methane hydrocarbons (NMCH) in the plume. A reason for the differences in our work compared to Petry et al. (1998) and Karol et al. (1997), could be a different distribution or amount of the hydrocarbons emitted, or a higher concentration in the ambient air. Moulik and Milford (1999) found that the ozone production in the plume was strongly influenced by the NMHC concentration in the ambient air. How the hydrocarbons are described and their lifetime in the chemistry schemes used in different plume models, will also influence the potential for ozone production.

\section{Conclusions}

Plumes emitted from two B747 aircraft have been modelled, and the calculated $\mathrm{NO}, \mathrm{CO}_{2}, \mathrm{HNO}_{3}$ and $\mathrm{HNO}_{2}$ were compared to near-field observations from the POLINAT database. The modelled $\mathrm{NO}_{x}$ mixing ratio on longer time scales was compared to a time evolution based on observations in more than 70 aircraft plumes (Schumann et al., 1998). The modelled NO and $\mathrm{CO}_{2}$ values in the innermost layers in the plume were from 90 to $30 \%$ and 70 to $60 \%$ higher than the observed values in the trailing vortices, respectively. As discussed in Schulte et al. (1997), observations within the trailing vortices were normally avoided due to high turbulence. It is therefore uncertain whether the highest possible $\mathrm{NO}$ and $\mathrm{CO}_{2}$ concentrations were measured. The modelled values were therefore in fair agreement with the observations.

In the model application, the main focus has been the conversion of the emitted $\mathrm{NO}_{x}$ to reservoir species, such as $\mathrm{HNO}_{3}, \mathrm{CH}_{3} \mathrm{NO}_{4}, \mathrm{HNO}_{4}, \mathrm{PAN}$ and $\mathrm{N}_{2} \mathrm{O}_{5}$. Contrary to Petry et al. (1998) and Karol et al. (1997) we found differences between a layered and a homogeneous approach. In our case, the inhomogeneous distribution of the emitted species caused different oxidising capacity in 
the various layers of the plume. At $50^{\circ} \mathrm{N}$ under summer condition for emissions at $7 \mathrm{UT}, 60 \%$ of the emitted $\mathrm{NO}_{x}$ remained after $15 \mathrm{~h}$. When considering a homogeneous plume, this amount was $43 \%$. In the latter case, the conditions for ozone production in the plume were more favourable, and the conversion of $\mathrm{NO}_{x}$ to $\mathrm{HNO}_{3}$ was higher. In addition, a higher conversion of $\mathrm{NO}_{x}$ to $\mathrm{CH}_{3} \mathrm{NO}_{4}$ was estimated compared to the layered approach. In our study, the difference in the chemical evolution between a layered versus a homogeneous plume, during a $15 \mathrm{~h}$ period, strongly depends on the time of emissions and background concentrations of ozone in the ambient air. Nevertheless, we found that the division of the plume into several layers revealed different conditions for the oxidising potential of $\mathrm{NO}_{x}$ in the plume. For the following work we therefore use a layered approach when investigating the chemical evolution in aircraft plumes.

\section{Acknowledgements}

This work was funded by the European Commission under contract number EV5V-CT93-0310 and by the Research Council of Norway, the Climate and Ozone program and the Norwegian Civil Aviation Administration. The authors would like to thank P. Schulte, H. Ziereis, F. Arnold and M. Klemm for providing the POLINAT-data and I. Ford for providing data on particles. I. Fløisand, S. Solberg, F. Flatøy, D.W. Arlander, K. J. Barrett and the reviewers have contributed with valuable comments and suggestions that improved the manuscript.

\section{References}

Arnold, F., Scheid, J., Stilp, Th., Schlager, H., Reinhardt, M.E., 1992. Measurements of jet aircraft emissions at cruise altitude. I: the odd nitrogen gases $\mathrm{NO}, \mathrm{NO}_{2}, \mathrm{HNO}_{2}, \mathrm{HNO}_{3}$. Geophysical Research Letters 19, 2421-2424.

Atkinson, R., Baulch, D.L., Cox, R.A., Hampson Jr., R.F., Kerr, J.A., Rossi, M.J., Troe, J., 1997. Evaluated kinetic, photochemical and heterogeneous data for atmospheric chemistry. Supplement V, IUPAC subcommittee on gas kinetic data evaluation for atmospheric chemistry. Journal of Physical and Chemical Reference Data 26, 521-1011.

Berntsen, T., Isaksen, I.S.A., 1994. A 3-D photochemical/transport model of the global troposphere. Technical Report 89, Institute of Geophysics, University of Oslo, Oslo, Norway.

Brasseur, G.P., Cox, R.A., Hauglustaine, D., Isaksen, I., Lelieveld, J., Lister, D.H., Sausen, R., Schumann, U., Whaner, A., Wiesen, P., 1998. European scientific assessment of the atmospheric effects of aircraft emissions. Atmospheric Environment 32, 2329-2418.

Böckle, S., Einecke, S., Hildenbrand, F., Orlemann, C., Schulz, C., Wolfrum, J., Sick, V., 1999. Laser-spectroscopy investigations of OH-radical concentrations in the exhaust plane of jet engines. Geophysical Research Letters 26, 1849-1852.
Danilin, M.Y., Ebel, A., Elbern, H., Petry, H., 1994. Evolution of the concentrations of trace species in an aircraft plume: trajectory study. Journal of Geophysical Research 99, 18951-18972.

Dürbeck, T., Gerz, T., 1995. Large-eddy simulation of aircraft exhaust plumes in the free atmosphere: effective diffusivities and cross-sections. Geophysical Research Letters 22, 3203-3206.

Dürbeck, T., Gerz, T., 1996. Dispersion of aircraft exhausts in the free atmosphere. Journal of Geophysical Research 101, 26007-26015.

Ford, I.J., Hayman, G.D., Kingdon, R.D., 1996. Plume and aerosol modelling for the POLINAT project. In: Schumann, U. (Ed.), Final Report, Pollution from Aircraft Emissions in the North Atlantic Flight Corridor (POLINAT). Report EUR 16978, European Commission, pp. 258-279.

Hanisco, T.F., Wennberg, P.O., Cohen, R.C., Anderson, J.G., Fahey, D.W., Keim, E.R., Gao, R.S., Wamsley, R.C., Donnelly, S.G., Del Negro, L.A., Salawitch, R.S., Kelly, K.K., Proffitt, M.H., 1997. The role of $\mathrm{HO}_{x}$ in super and subsonic aircraft exhaust plumes. Geophysical Research Letters 24, 65-68.

Hesstvedt, E., Hov, Ø., Isaksen, I.S.A., 1978. Quasi-steady-state approximations in air pollution modelling. Comparison of two numerical schemes of oxidant prediction. International Journal of Chemical Kinetics 10, 971-994.

Hoshizaki, H., Anderson, L.B., Conti, R.J., Farlow, N., Meyer, J.W., Overcamp, T., Redler, K.O., Watson, V., 1975. Aircraft wave microscale phenomena. In: CIAP Monograph 3, The Stratosphere Perturbed by Propulsion Effluents (Chapter 2) DOT-TST-75-53, U.S. Department of Transportation, Washington D.C., U.S.A., 77pp.

Intergovernmental Panel on Climate Change (IPPC), 1999. In: Penner, J.E., Lister, D.H., Griggs, D.J., Dokken, D.J., McFarland, M. (Eds.), Aviation and the Global Atmosphere. Cambridge University Press, New York, 373pp.

JPL, 1997. Chemical Kinetics and Photochemical Data for Use in Stratospheric Modeling. Evaluation Number 12, NASA, JPL Publication No. 97-4.

Kärcher, B., 1995. A trajectory box model for aircraft exhaust plumes. Journal of Geophysical Research 100, 18835-18844.

Kärcher, B., 1997. Heterogeneous chemistry in aircraft wakes: constraints for uptake coefficients. Journal of Geophysical Research 102, 19119-19135.

Kärcher, B., Hirschberger, M.M., Fabian, P., 1996. Small-scale chemical evolution of aircraft exhaust species at cruising altitudes. Journal of Geophysical Research 101, 15169-15190.

Karol, I.L., Ozolin, Y.E., 1994. Small- and medium-scale effects on high-flying aircraft exhausts on the atmospheric composition. Annales Geophysicae 12, 979-985.

Karol, I.L., Ozolin, Y.E., Rozanov, E.V., 1997. Box and Gaussian plume models of the exhaust composition evolution of subsonic transport aircraft in and out the flight corridor. Annales Geophysicae 15, 88-96.

Konopka, P., 1995. Analytical Gaussian solutions for anisotropic diffusion in a linear shear flow. Journal of Non-Equilibrium Thermodynamics 20, 78-91.

Kraabøl, A.G., Stordal, F., 2000. Modelling chemistry in aircraft plumes 2: the chemical conversion of $\mathrm{NO}_{x}$ to reservoir species under different conditions. Atmospheric Environment 34, 3951-3962. 
Kraabøl, A.G., Stordal, F., Konopka, P., Knudsen, S., 1999. The NILU aircraft plume model: a technical description. NILU TR 4/99, Norw. Inst. Air Res., 2027-Kjeller, Norway (library@NILU.no).

Louisnard, N.F., Garnier, P., Taleb, D., 1995. Physics and chemistry in the aircraft wake, application to a test case. In: Schumann, U. (Ed.), The Impact of $\mathrm{NO}_{x}$ Emissions from Aircraft upon the Atmosphere at Flight Altitudes $8-15 \mathrm{~km}$ (AERONOX), pp. 269-296.

Meijer, E.W., Beck, J.P., Velders, G.J.M., 1996. Modelling gas phase and heterogeneous conversion of nitrogen oxides in the exhaust plume of an aircraft, RIVM 72201010 , p.79.

Möllhoff, M., Hendricks, J., Lippert, E., Petry, H., Sausen, R., 1996. Model analyses of the chemical conversion of exhaust species in the expanding plumes of subsonic aircraft. Proceedings of an International Colloquium on Impact of Aircraft Emissions upon the Atmosphere, Paris, 15-18 October 1996, pp. 521-526.

Moulik, M.D., Milford, J.B., 1999. Factors influencing ozone chemistry in subsonic aircraft plumes. Atmospheric Environment 33, 869-880.

Petry, H., Hendricks, J., Möllhof, M., Meijer, Ebel, A., Sausen, R., 1998. Chemical conversion of subsonic aircraft emissions in the dispersing plume: calculation of effective emission indices. Journal of Geophysical Research 103, 5759-5772.
Pleijel, K., Moldanovä, J., Andersson-Sköld, Y., 1993. Chemical modelling of an aeroplane exhaust plume in the free troposphere. Technical Report B1105, IVL, Box 470 86, SE-402 58 Göteborg, Sweden.

Schlager, H., Konopka, P., Schulte, P., Schumann, U., Ziereis, H., Arnold, F., Klemm, M., Hagen, D.E., Whitefield, P.D., Ovalez, J., 1997. In situ observations of aircraft emissions signatures in the North Atlantic flight corridor. Journal of Geophysical Research 102, 10739-10750.

Schulte, P., Schlager, H., Ziereis, H., Schumann, U., Baughcum, S., Deidewig, F., 1997. $\mathrm{NO}_{\mathrm{x}}$ emission indices of subsonic long-range aircraft at cruise altitude: in situ measurements and predications. Journal of Geophysical Research 102, 21431-21442.

Schumann, U., Konopka, P., Baumann, R., Busen, R., Gerz, T., Schlager, H., Schulte, P., Volkert, H., 1995. Estimation of diffusion parameters of aircraft exhaust plumes near the tropopause from nitric oxide and turbulence measurements. Journal of Geophysical Research 100, 14147-14162.

Schumann, U., Schlager, H., Arnold, F., Baumann, R., Haschberger, P., Klemm, O., 1998. Dilution of aircraft plumes at cruise altitudes. Atmospheric Environment 32, 3097-3103.

Tremmel, H.G., Schlager, H., Konopka, P., Schulte, P., Arnold, F., Klemm, M., Droste-Franke, B., 1998. Observations and model calculations of jet aircraft exhaust products at cruise altitude and inferred initial $\mathrm{OH}$ emissions. Journal of Geophysical Research 103, 10803-10816. 